\title{
BIODISPONIBILIDADE DO $\beta$-CAROTENO DA FOLHA DESIDRATADA DE MANDIOCA (Manihot esculenta Crantz) ${ }^{1}$
}

\author{
Claudia Isabel ORTEGA-FLORES ${ }^{2}$, Maria Aparecida LOPES DA COSTA², \\ Marney Pascoli CEREDA ${ }^{2}$, E Marilene De Vuono CAMARGO PENTEADO ${ }^{2, *}$
}

\section{RESUMO}

Com o objetivo de verificar a biodisponibilidade do $\beta$-caroteno da folha de mandioca (Manihot esculenta Crantz) foi realizado um ensaio biológico baseado no modelo de esgotamento das reservas hepáticas de vitamina A em ratos. Um grupo de ratos depletados de vitamina A hepática recebeu folha desidratada de mandioca como fonte $\beta$-caroteno durante 25 dias, e foram comparados com um grupo que recebeu ração com vitamina $A$, outro grupo com ração sem vitamina A e um último grupo com $\beta$-caroteno. O grupo Zero foi constituído de 8 animais que receberam durante 15 dias ração à base de caseina, deficiente de vitamina A. Ao final do experimento todos os animais foram sacrificados e seus figados e plasmas analisados por Cromatografia Liquida de Alta Eficiência (CLAE), sendo verificado que a biodisponibilidade do $\beta$-caroteno da folha desidratada de mandioca foi baixa.

Palavras-chave: biodisponibilidade; $\beta$-caroteno; vitamina A; folhas de mandioca.
\end{abstract}

\section{SUMMARY}

BIOAVAILABILITY OF $\beta$-CAROTENE IN DEHYDRATED CASSAVA LEAVES (Manihot esculenta Crantz). The biological availability of $\beta$ carotene in cassava leaves (Manihot esculenta Crantz), was verified by means of an assay based on the hepatic depletion of vitamin A reserves model in rats. Rats depleted of hepatic vitamin A received dehydrated cassava leaves as $\beta$-carotene source for 25 days and were compared to groups that received diets with vitamin A, $\beta$-carotene and without vitamin A. The Zero group was formed of 8 animals that received a diet based on casein, lacking vitamin A, during 15 days. At the end of the experiment, all animals were killed and their livers, serum and feces were analyzed by high performance liquid chromatography (HPLC), and it was verified that the bioavailability of $\beta$ carotene of dehydrated cassava leaves was lower.

Keywords: bioavailability; $\beta$-carotene; vitamin A; cassava leaves.

\section{1 - INTRODUÇÃO}

No Brasil, as folhas e a parte aérea da mandioca encontram-se disponiveis em áreas de plantio e podem desempenhar um papel importante na nutrição humana e animal, pois como é sabido, apresentam altos teores de proteina, vitaminas ( $\beta$-caroteno, vitamina $C$ ) e minerais [7].

A ocorrência de carotenóides pró-vitamínicos A em variedades de mandioca de polpa amarela tem despertado o interesse de pesquisadores já que estes poderão contribuir em regiões onde existe a deficiência de vitamina A $[16,18]$. Além disso, trabalhos têm mostrado que a parte aérea da mandioca é rica em $\beta$-caroteno $[1,7]$.

$\mathrm{Na}$ literatura, tem sido questionada nos últimos anos, a biodisponibilidade e/ou bioconversão dos carotenóides em vitamina A ativa $[5,26]$. Estudos têm demonstrado que em folhas verdes, o $\beta$-caroteno se encontra menos disponivel que em óleos, frutas ou suplementos alimenticios. Vegetais de folhas verdes são fonte pobre em vitamina A principalmente para pessoas desnutridas que apresentam dificuldades em transformar carotenóides em vitamina A [12].

BURRI [6] em 1997, sugere programas para melhorar o estado de vitamina A através do consumo de vegetais de

1. Recebido para publicação em 06/08/2002. Aceito para publicação em 13/05/2003 (000922). Parte da Tese de Doutorado da primeira autora 2 Depto.Alimentos e Nutrição Experimental da Faculdade de Ciências Farmacêticas da Universidade de São Paulo. Av. Prof. Lineu Prestes, 580 -Bloco 14. CEP 05508-900 - São Paulo.E-mail:devuono@usp.br ${ }^{3}$ Centro de Raizes Tropicais (CERAT) da Unesp/Botucatu.

* A quem a correspondência deve ser enviada. folhas verdes. Entretanto, suplementação com vitamina A ou cápsulas de $\beta$-caroteno podem ser uma melhor alternativa. Desta forma, estudos de biodisponibilidade de carotenóides são necessários para fornecer informações verdadeiras sobre o valor vitamínico A dos alimentos.

\section{2 - MATERIAL E MÉTODOS}

\section{1 - Delineamento experimental}

Folhas de mandioca (Manihot esculenta Crantz) CV Branca de Santa Catarina, foram obtidas no Centro de Raizes Tropicais (CERAT) da UNESP campus de Botucatu, na safra de 1997. As amostras foram colhidas manualmente, com os ramos da planta toda, e destacadas junto com os pecíolos sem qualquer classificação e submetidas a desidratação à sombra $\left(25^{\circ} \mathrm{C}\right)$ durante duas semanas.

No ensaio biológico para o estudo de biodisponibilidade do $\beta$-caroteno das folhas de mandioca foram utilizados ratos da linhagem Wistar (Rattus norvergicus, linhagem Wistar), provenientes da colônia do biotério da Faculdade de Ciências Farmacêuticas da Universidade de São Paulo.

O estudo foi baseado no modelo de esgotamento das reservas hepáticas de vitamina $\mathrm{A}$ em ratos sugerido por SWEENEY \& MARCH [25]. As rações para o ensaio biológico foram elaboradas segundo as recomendações do "American Institute of Nutrition" AIN-93 [20]. O delineamento experimental foi inteiramente casualizado e o ensaio foi subdividido em 2 períodos: depleção e repleção ou testes. 
A fase de depleção durou 5 semanas e a de teste 25 dias. Para o período de depleção ratas adultas receberam ração ad libitum à base de caseina deficiente em vitamina A. As ratas amamentaram uma média de 10 filhotes, por um periodo de 21 dias. Ao final deste periodo os filhotes foram separados das mães e distribuidos em gaiolas individuais formando cinco grupos diferentes com 8 animais cada um, que receberam uma ração ad libitum à base de caseina deficiente em vitamina A, com a finalidade de eliminar possiveis reservas hepáticas desta vitamina que poderiam ter sido passadas pelas ratas aos filhotes durante a lactação. Este periodo durou 15 dias. No final da quinta semana os animais do "grupo Zero" foram sacrificados com a finalidade de se avaliar as reservas de vitamina A.

Os grupos formados passaram a receber diferentes fontes de vitamina A, foram constituídos quatro grupos contendo 8 ratos cada, assim: "grupo - caroteno", "grupo Vitamina A", "grupo Folha de Mandioca" recebendo por tanto $\beta$-caroteno e "grupo sem Vitamina $A$ ".

O crescimento dos animais foi acompanhado durante todo o estudo por meio de pesagens semanais. A ingestão das rações, a troca de água dos bebedouros e a coleta de fezes foram acompanhadas, renovadas e coletadas a cada dois dias no mesmo horário. Ao final do experimento, todos os animais foram sacrificados para análise.

\section{2 - Determinação dos carotenóides da folha de mandioca}

O método utilizado para a determinação de carotenóides da folha desidratada de mandioca foi baseado no procedimento descrito por RODRIGUEZ et al. [23]. Todas as etapas das análises foram realizadas ao abrigo da luz e os extratos de carotenóides foram protegidos com tecido escuro e/ou papel alumínio.

\section{3 - Colheita do material biológico}

Para proceder a colheita do sangue e a retirada do figado, os animais foram anestesiados por inalação com éter etílico p. a. A colheita do sangue foi feita através da artéria aorta abdominal. O sangue foi centrifugado a 3000 rpm por 15 minutos a $4^{\circ} \mathrm{C}$. O plasma assim obtido, armazenado em freezer a $-70^{\circ} \mathrm{C}$ até a análise.

Os figados foram retirados, lavados com solução salina $0,9 \% \mathrm{p} / \mathrm{v}$ resfriada, secos em papel filtro, pesados, subdivididos em lóbulos, utilizando-se o lóbulo direito para análise, acondicionados em papel de alumínio, congelados em nitrogênio líquido e conservados em freezer a $-70^{\circ} \mathrm{C}$ até a análise.

As fezes foram secadas em estufa ventilada a $45^{\circ} \mathrm{C}$. Após a secagem as fezes foram limpas, pesadas e pulverizadas em moinho de aço inoxidável.

QUADRO 1. Condições cromatográficas utilizadas na análise do Retinol e $\beta$-caroteno no fígado, plasma e fezes.

\begin{tabular}{|c|c|c|c|c|c|c|c|}
\hline $\begin{array}{l}\text { Material } \\
\text { biológico }\end{array}$ & Coluna & Fase móvel & $\begin{array}{l}\text { Solvente } \\
\text { da amostra }\end{array}$ & Detector & Fluxo & $\begin{array}{l}\text { Volume } \\
\text { de } \\
\text { injeção }\end{array}$ & Referência \\
\hline \multicolumn{8}{|l|}{ Fígado } \\
\hline Retinol & $\begin{array}{l}\text { Sílica (Shimadzu) } \\
\text { partículas de } 5 \mu \mathrm{m} \\
6 \mathrm{~mm} \text { diâmetro } \\
15 \mathrm{~cm} \text { comprimento }\end{array}$ & $\begin{array}{l}\text { Hexano: } \\
\text { Isopropanol } \\
(99: 1)\end{array}$ & Hexano & $\begin{array}{l}\text { Fluore scência } \\
\lambda \text { de excitação } \\
330 \mathrm{~nm} \\
\lambda \text { de emissão } \\
480 \mathrm{~nm}\end{array}$ & $2 \mathrm{~mL} / \mathrm{min}$ & $20 \mu \mathrm{L}$ & $\begin{array}{l}\text { RETTENMAIER } \\
\text { \& SHÜEP, [21]. }\end{array}$ \\
\hline$\beta$-caroteno & $\begin{array}{l}\text { C18 (Vydac,201TP54) } \\
\text { partículas de } 5 \mu \mathrm{m} \\
4,6 \mathrm{~mm} \text { diâmetro } \\
25 \mathrm{~cm} \text { comprimento }\end{array}$ & $\begin{array}{l}\text { Metanol: } \\
\text { Acetonitrila: } \\
\text { Água } \\
(88: 9: 3)\end{array}$ & Metanol & $\begin{array}{l}\text { "Photodiodo } \\
\text { array" } \\
\text { (UV/Visível) } \\
\lambda \text { máx. }=452 \mathrm{~nm}\end{array}$ & $2 \mathrm{~mL} / \mathrm{min}$ & $20 \mu \mathrm{L}$ & $\begin{array}{l}\text { SCHMITZ et al. } \\
{[24] \text {. }}\end{array}$ \\
\hline \multicolumn{8}{|l|}{ Plasma } \\
\hline Retinol & $\begin{array}{l}\text { Sílica (Shimadzu) } \\
\text { partículas de } 5 \mu \mathrm{m} \\
6 \mathrm{~mm} \text { diâmetro } \\
15 \mathrm{~cm} \text { comprimento }\end{array}$ & $\begin{array}{l}\text { Acetonitrila: } \\
\text { Metanol: } \\
\text { Clorofórmio } \\
(47: 47: 6)\end{array}$ & Hexano & $\begin{array}{l}\text { Fluorescência } \\
\lambda \text { de excitação } \\
330 \mathrm{~nm} \\
\lambda \text { de emissão } \\
480 \mathrm{~nm}\end{array}$ & $1,5 \mathrm{~mL} / \mathrm{min}$ & $20 \mu \mathrm{L}$ & $\begin{array}{l}\text { THURNHAM, } \\
\text { SMITH \& } \\
\text { FLORA, [27]. }\end{array}$ \\
\hline$\beta$-caroteno & $\begin{array}{l}\text { C18 (Vydac,201TP54) } \\
\text { partículas de } 5 \mu \mathrm{m} \\
4,6 \mathrm{~mm} \text { diâmetro } \\
25 \mathrm{~cm} \text { comprimento }\end{array}$ & $\begin{array}{l}\text { Metanol: } \\
\text { Acetonitrila: } \\
\text { Água } \\
(88: 9: 3)\end{array}$ & Metanol & $\begin{array}{l}\text { "Photodiodo } \\
\text { array" } \\
\text { (UV/Visível) } \\
\lambda \text { máx. }=452 \mathrm{~nm}\end{array}$ & $2 \mathrm{~mL} / \mathrm{min}$. & $20 \mu \mathrm{L}$ & $\begin{array}{l}\text { SCHMITZ et al. } \\
{[24]}\end{array}$ \\
\hline \multicolumn{8}{|l|}{ Fezes } \\
\hline Retinol & $\begin{array}{l}\text { Sílica (Shimadzu) } \\
\text { partículas de } 5 \mu \mathrm{m} \\
6 \mathrm{~mm} \text { diâmetro } \\
15 \mathrm{~cm} \text { comprimento }\end{array}$ & $\begin{array}{l}\text { Hexano: } \\
\text { Isopropanol } \\
(99: 1)\end{array}$ & Hexano & $\begin{array}{l}\text { Fluore scência } \\
\lambda \text { de excitação } \\
330 \mathrm{~nm} \\
\lambda \text { de emissão } \\
480 \mathrm{~nm}\end{array}$ & $2 \mathrm{~mL} / \mathrm{min}$ & $20 \mu \mathrm{L}$ & $\begin{array}{l}\text { RETTENMAIER } \\
\text { \& SHÜEP, [21] }\end{array}$ \\
\hline$\beta$-caroteno & $\begin{array}{l}\text { C18 (Capcell Pack- } \\
\text { Shiseido) } \\
\text { partículas de } 5 \mu \mathrm{m} \\
4,6 \mathrm{~mm} \text { diâmetro } \\
25 \mathrm{~cm} \text { comprimento }\end{array}$ & $\begin{array}{l}\text { Acetonitrila: } \\
\text { Diclorometano: } \\
\text { Metanol } \\
(70: 20: 10)\end{array}$ & Metanol & $\begin{array}{l}\text { "Photodiodo } \\
\text { array" } \\
\text { (UV/Visível) } \\
\lambda \text { máx. }=452 \mathrm{~nm}\end{array}$ & $2 \mathrm{~mL} / \mathrm{min}$. & $20 \mu \mathrm{L}$ & $\begin{array}{l}\text { AL-ABDULAY } \\
\& \text { SIMPSON, [2]. }\end{array}$ \\
\hline
\end{tabular}




\section{4 - Determinação do Retinol e do $\beta$-caroteno no material biológico}

As análises de retinol e $\beta$-caroteno no figado, plasma e fezes foram realizadas através de cromatografia líquida de alta eficiência (CLAE). O método empregado para a extração do $\beta$-caroteno e retinol do material biológico (figado, plasma e fezes) foi baseado nos trabalhos de ALABDULAY \& SIMPSON [2].

As condições cromatográficas utilizadas na análise do retinol e $\beta$-caroteno no figado, plasma e fezes encontram-se no Quadro 1.

\section{5 - Análises químicas}

As análises de nitrogênio foram realizadas segundo a AOAC [3], sob nitrogênio igual a 6,25. A umidade, resíduo mineral fixo e extrato etéreos foram analisados segundo IAL [15]. As fibras foram analisadas pelo método gravimétrico enzimático descrito por PROSKY [19] e modificado por FILISETTI-COZZI \& LAJOLO [14].

\section{6 - Análise estatística}

A análise dos resultados obtidos foi feita utilizandose o teste de Kruskall-Wallis, que equivale a ANOVA (OneWay Analysis of Variance) não paramétrico. Quando se verificaram diferenças significativas foi aplicado o teste de Mann-Whitney (não paramétrico). Todos as análises foram realizadas com nivel de significância de $5 \%(p<0,05)$ [10].

\section{3 - RESULTADOS E DISCUSSÃO}

Para os cálculos da quantidade de vitamina A a ser utilizada nas rações empregou-se o valor do $\beta$-caroteno total das folhas desidratadas que foi de $2073 \mu \mathrm{g}$ de retinol/ 100g. As rações foram analisadas no começo do ensaio biológico, e as suas composições centesimais estão apresentadas na Tabela 1 .

TABELA 1. Composição centesimal das rações expressa em g/ 100g*.

\begin{tabular}{|c|c|c|c|c|c|c|}
\hline $\begin{array}{l}\text { Determinação } \\
\text { Ração } \\
\end{array}$ & Umidade & $\begin{array}{c}\text { Resíduo } \\
\text { Mineral Fixo } \\
\end{array}$ & Proteína & $\begin{array}{c}\text { Extrato } \\
\text { Etéreo } \\
\end{array}$ & $\begin{array}{r}\text { Fibra } \\
\text { Total } \\
\end{array}$ & $\begin{array}{c}\text { Carboidratos } \\
\text { Totais }\end{array}$ \\
\hline Sem Vitamina $A$ & $8,60 \pm 0,12$ & $2,57 \pm 0,05$ & $21,38 \pm 0,07$ & $7.16 \pm 0,06$ & 5,22 & 55,07 \\
\hline Vitamina $A$ & $9,01 \pm 0,16$ & $2,49 \pm 0,03$ & $20,47 \pm 0,03$ & $7,02 \pm 0,02$ & 4,78 & 56,23 \\
\hline$\beta$-Caroteno & $8,31 \pm 0,06$ & $2,45 \pm 0,05$ & $19,56 \pm 0,30$ & $6,84 \pm 0,11$ & 4,98 & 57,86 \\
\hline Folha de Mandioca & $8,24 \pm 0,02$ & $2,47 \pm 0,03$ & $20,82 \pm 0,05$ & $7,72 \pm 0,04$ & 5,21 & 55,54 \\
\hline
\end{tabular}

* Médias de três determinações \pm desvio padrão

O acompanhamento do ganho de peso dos animais foi realizado durante todo o experimento. Pode-se observar na Tabela 2 que as diferenças entre os ganhos de peso dos grupos que receberam "Folha de Mandioca", " $\beta$-caroteno" e "Vitamina $A$ " foram muito pequenas sendo estas diferenças estatisticamente não significativas. $O$ grupo que apresentou o menor ganho de peso foi o grupo que recebeu ração "sem Vitamina $A$ " sendo que esta diferença foi estatisticamente significativa em relação aos demais grupos.
O "grupo sem Vitamina A" apresentou 37\% do crescimento do "grupo Vitamina A", sendo que este grupo de ratos apresentou perda de peso durante o periodo de repleção e dois dos ratos morreram antes de terminar o experimento.

Como é sabido, a deficiência de vitamina A afeta a proliferação e diferenciação celular, portanto, a sua deficiência afeta o crescimento. Estudos têm mostrado que animais submetidos a uma ração deficiente em vitamina A crescem até que suas reservas vitamínicas sejam consumidas, interrompendo aí o crescimento, apresentando então um "plateau" na curva de crescimento, seguido de perda de peso e morte do animal [4]. Isto também pode ser atribuído em parte a uma perda do apetite devido a mudanças nas células epiteliais. A diminuição do consumo de alimentos tem sido considerada como um sinal prévio da hipovitaminose A em ratos [4].

TABELA 2. Médias e desvios padrão do peso inicial, final, e consumo total de ração dos animais expressos em gramas durante a repleção de 25 dias.

\begin{tabular}{|c|c|c|c|}
\hline Grupos & $\begin{array}{l}\text { Peso inicial } \\
(\mathrm{g})\end{array}$ & $\begin{array}{l}\text { Peso final } \\
(\mathrm{g})\end{array}$ & $\begin{array}{c}\text { Consumo de ração } \\
(\mathrm{g})\end{array}$ \\
\hline Vitamina $A^{*}$ & $163,77 \pm 15,08 \mathrm{a}$ & $278,46 \pm 15,37 b$ & $410,06 \pm 40,77^{d}$ \\
\hline Folha de Mandioca & $149,35 \pm 19,77$ a & $265,22 \pm 28,00 \mathrm{~b}$ & $415,94 \pm 34,65 \mathrm{~d}$ \\
\hline$\beta$-caroteno & $154,93 \pm 16,20 \mathrm{a}$ & $261,46 \pm 21,61 \mathrm{~b}$ & $402,18 \pm 33,42 \mathrm{~d}$ \\
\hline Sem vitamina $A^{* *}$ & $159,49 \pm 10,13 \mathrm{a}$ & $154,57 \pm 15,18^{\mathrm{c}}$ & $312,09 \pm 94,00 \mathrm{e}$ \\
\hline
\end{tabular}

Média de 8 ratos

** Média de 7 ratos

a - diferença não estatisticamente significativa, $(p<0,05)$ com relação ao peso inicial - diferença não estatisticamente significativa, $(\mathrm{p}<0,05) \mathrm{com}$ relação ao peso final $\mathrm{d}$ - diferença não estatisticamente significativa, $(\mathrm{p}<0,05)$ com relação ao consumo de ração

diferença estatisticamente significativa, $(p<0,05)$ com relação ao consumo de ração

Durante o período de repleção o consumo de ração dos grupos "Vitamina A", "Folha de Mandioca" e " $\beta$-caroteno" ficou muito próximo e sem diferença estatística significativa. O "grupo sem Vitamina A" consumiu menor (significativa a $\mathrm{p}<0,05)$ quantidade de ração em relação aos outros três grupos, como pode ser observado na $\mathrm{Ta}$ bela 2.

Os resultados mostram que o grupo que recebeu ração "sem Vitamina A" apresentou baixo aproveitamento da caseina da dieta. Isto pode ser atribuido em parte a perda de apetite e porque ração desbalanceada tem em geral menor consumo.

Após o período de cinco semanas, recebendo uma ração sem Vitamina $A$, foram encontradas pequenas quantidades de retinol nos figados demonstrando que os animais estavam depletados da vitamina, como pode ser observado no "grupo Zero" na Tabela 3.

O grupo vitamina A apresentou o maior estoque de retinol hepático demonstrando melhor absorção de vitamina purificada. As diferenças entre o retinol hepático do "grupo Vitamina A" e demais grupos experimentais foram estatisticamente significativas (Tabela 3). 
O conteúdo de retinol encontrado no figado do "grupo Folha de Mandioca" foi 4 vezes menor em relação ao grupo " $\beta$-caroteno" sendo a diferença significativa (Tabela 3). Isto pode ser explicado pelo fato do $\beta$-caroteno na folha de mandioca estar dentro de uma matriz complexa. DE PEE \& WEST [11], DE PEE et al. [12] discutiram a baixa biodisponibilidade do $\beta$-caroteno em vegetais de folhas verdes e argumentam que a baixa biodisponibilidade seja devida aos complexos carotenóides-proteina no cloroplasto.

As folhas de mandioca utilizadas neste experimento passaram por desidratação e trituração. Segundo DE PEE $\&$ WEST [11], tais deveriam aumentar a biodisponibilidade do $\beta$-caroteno. É possivel que o elevado teor de fibra das folhas de mandioca tenham diminuido a biodiponibilidade do $\beta$-caroteno, como demonstrou ROCK \& SWENSEID [22] para humanos e ERDMAN, FAHEY \& WHITE [13] para animais.

TABELA 3. Teores médios e desvios padrão, expressos em $\mu \mathrm{g} / \mathrm{g}$ ou $\mu \mathrm{g} / \mathrm{mL}$, de retinol e $\beta$ - caroteno em fígado, plasma e fezes dos ratos dos diferentes grupos estudados.

\begin{tabular}{|c|c|c|c|c|}
\hline Grupos & $\begin{array}{c}\text { Retinol no Fígado } \\
\mu \mathrm{g} / \mathrm{g}\end{array}$ & $\begin{array}{c}\text { Retinol total no } \\
\text { Fígado } \\
\mu \mathrm{g} / \mathrm{g} \\
\end{array}$ & $\begin{array}{c}\text { Retinol no Plasma } \\
\mu \mathrm{g} / \mathrm{mL}\end{array}$ & $\begin{array}{c}\beta \text { - caroteno nas } \\
\text { Fezes } \\
\mu \mathrm{g} / \mathrm{g}\end{array}$ \\
\hline Zero* & $0,21 \pm 0,11 \mathrm{cdd}$ & $1,80 \pm 0,71 \mathrm{c}, \mathrm{d}$ & $0,09 \pm 0,03 c, d$ & ---- \\
\hline Vitamina $A^{* *}$ & $11,49 \pm 3,52^{a, d}$ & $125,37 \pm 29,86^{a, d}$ & $1,17 \pm 0,58 \mathrm{a,d}$ & nd \\
\hline Fo iha de Mondioca & $0,26 \pm 0,14 b, c, d$ & $2,58 \pm 1,40 \mathrm{~b}, c, \mathrm{~d}$ & $0,63 \underset{\mathrm{a}, \mathrm{a}, \mathrm{d}}{ \pm 0,42}$ & $0,20 \pm 0,05$ \\
\hline$\beta$-caroteno & $1,03 \pm 0,65 \mathrm{a}, \mathrm{c}$ & $10,12 \pm 7,51^{\mathrm{a}, \mathrm{c}}$ & $0,53 \pm 0,32 \mathrm{a}, \mathrm{c}$ & nd \\
\hline $\begin{array}{l}\text { Sem Vitamina } \\
\mathrm{A}^{* * * *}\end{array}$ & $0,05 \pm 0,08^{a, c, d}$ & $0,35 \pm 0,57 \mathrm{a}, \mathrm{c}, \mathrm{d}$ & $0,06 \underset{b, c, d}{ \pm 0,02}$ & nd \\
\hline
\end{tabular}

Média de três determinações \pm desvio padrão

nd= não detectado

Média de 8 ratos

* "Grupo Zero": corresponde à animais depletados em Vitamina A por 5 semanas ** Média de 7 ratos

*** Média de 6 ratos

a - diferença estatisticamente significativa, quando comparado com a média do "grupo Zero" $(\mathrm{p}<0,05)$

"- diferença não estatisticamente significativa, quando comparado com a média do grupo Zero" (p<0,05)

"grupo Vitamina $A^{\prime \prime}(\mathrm{p}<0,05)$

po -caroteno" $(\mathrm{p}<0,05)$

No presente trabalho, não foi detectado $\beta$-caroteno em nenhum dos figados analisados. Segundo PARKER [17], o rato incorpora pequenas quantidades de $\beta$-caroteno da dieta em seus tecidos. Para WANG [29] a maioria das espécies animais (ratos, coelhos, galinhas e porcos) convertem o $\beta$-caroteno da dieta em retinóides no intestino delgado sem absorção significativa do $\beta$-caroteno intacto.

Com relação ao plasma os teores de retinol do "grupo Folha de Mandioca" apresentou teores significativamente maiores que os do "grupo $\beta$-caroteno". O "grupo Vitamina A" apresentou teores de retinol cerca de 2 vezes acima em relação aos grupos "Folha de Mandioca" e " $\beta$-caroteno" (Tabela 3). O "grupo sem Vitamina A" apresentou valores minimos de retinol no figado e no plasma demonstrando que foram esgotadas as reservas hepáticas da vitamina.
COSTA et al. [8, 9], TEE et al. [28], não detectaramcaroteno nos plasmas analisados. No presente trabalho, somente o "grupo Folha de Mandioca" apresentou pequenos teores de $\beta$-caroteno nas fezes, indicando que parte do $\beta$-caroteno não foi absorvida.

A quantidade de $\beta$-caroteno oferecida aos animais do "grupo Folha de Mandioca" foi suficiente para a manutenção do crescimento e sobrevivência. Não foram observados sinais de deficiência de vitamina $A$, porém, a quantidade era insuficiente para o armazenamento de retinol hepático.

\section{4 - CONCLUSÕES}

- Conclui-se que a biodisponibilidade do $\beta$-caroteno da folha de mandioca é mais baixa em relação ao $\beta$-caroteno sintético.

- O $\beta$-caroteno da folha de mandioca e sintético foram transformados em retinol porque não houve detecção daquele no plasma e figado dos ratos.

- A quantidade de $\beta$-caroteno da folha de mandioca oferecida para os ratos foi suficiente para o crescimento durante 25 dias e não foi suficiente para armazenar retinol no figado.

\section{5 - REFERÊNCIAS BIBLIOGRÁFICAS}

[1] ADEWUSI, S.R.A., BRADBURY, J.H. Carotenoids in cassava: comparison of open column and HPLC methods of analysis. J. Sci. Food Agric., London, v. 62, p. 375383, 1993.

[2] AL-ABDULAY, A.B., SIMPSON, K.L. Reversed-phase column chromatography for the determination of retinol in some foods. J. Micronutr. Anal., Barking, v. 5, p. 161-169, 1989.

[3] ASSOCIATION OF OFFICIAL ANALYTICAL CHEMISTS. Official methods of analysis of AOAC International. 17. ed. Washington, 1995. (Method 96722)

[4] BONDI, A., SKLAN, D. Vitamin A and carotene in animal nutrition. Prog. Food Nutr. Sci., Oxford, v. 8, p. 165191, 1984.

[5] BULUX, J., SERRANO, J.Q. de, PEREZ, R., RIVERA, C., LOPEZ, C.Y., SOLOMONS, N. W. Studies on the bioconversion and bioavailability of $\beta$-carotene in Guatemalan school children. Eur. J. Clin. Nutr., London, v. 50, n. 3, p. S76-S77, 1996.

[6] BURRI, B.J. Bet $\alpha$-carotene and human health: a review of current research. Nutr. Res., New York, v. 17, n. 3, p. 547-580, 1997.

[7] CARVALHO, V.D., CHAGAS, S.J.R., MORAIS, A.R., PAULA, M.B. Efeitos da época de colheita na produtividade e teores de vitamina $\mathrm{C}$ e b caroteno da parte aérea de cultivares de mandioca(Manihot esculenta Crantz). Rev. Bras. Mandioca, Cruz das Almas. v. 8, n. 1, p. 25-35, 1989.

[8] COSTA, M.A.L., ORTEGA-FLORES, C.I., PENTEADO, M.V.C. Interação dos isômeros todo-trans, 9-cis e 13-cis do $\beta$ caroteno na bioconversão desses em vitamina. Brazilian Journal of Pharmaceutical Science, São Paulo, v. 37, n. 1, jan/abr., p. 19-25, 2001.

[9] COSTA, M.A.L., ORTEGA-FLORES, C.I., PENTEADO, M.V.C. Fatores de conversão dos isômeros 9-cis e 13-cis do $\beta$ - 
caroteno em retinol. J. Brazilian Soc. Food Nutr. São Paulo, v. 21, jun., p. 73-86, 2001.

[10] CONOVER, W.J. Practical non parametric statisticals. 2 ed. New York: Wiley, 1980, p. 229-232.

[11] DE PEE, S., WEST, C.E. Dietary carotenoids and their role in combating vitamin A deficiency: a review of the literature. Eur. J. Clin. Nutr., London, v. 50, n. 3, p. S39-S53, 1996.

[12] DE PEE, S., WEST, C.E., MUHILAL, KARYADI, D., HAUTVAST, J.G.A.J. Lack of improvement in vitamin A status with increased consumption of dark-green leafy vegetables. Lancet, London, v. 346, p. 75-81, 1995.

[13] ERDMAN, J.W., FAHEY, G.C., WHITE, C.B. Effects of purified dietary fiber sourceson bet $\alpha$-carotene utilization by the chick. J. Nutr., Philadelphia, v. 116, p. 24152423, 1986.

[14] FILISETTI-COZZI, T.M.C.C., LAJOLO, F.M. Fibra alimentar insolúvel, solúvel em alimentos brasileiros. Rev Farm. Bioquím. Univ. São Paulo, São Paulo, v. 27, n. 1, p. 8399, 1991.

[15] INSTITUTO ADOLFO LUTZ Normas analíticas do Instituto Adolfo Lutz. 3. ed. São Paulo, 1985. v. 1, p. 21-22, 27-28, 42-43.

[16] ORTEGA-FLORES, C.I., PENTEADO, M.V.C. Carotenóides com atividade pró-vitamínica A em cultivares de mandioca (Manihot esculenta Crantz). Rev. Far. Bioquím. Univ. São Paulo, São Paulo, v. 28, n. 1, p. 51-60, 1992.

[17] PARKER, R.S. Absorption, metabolism and transport of carotenoids. FASEB J., Bethesda, v. 10, p. 542-551, 1996

[18] PENTEADO, M.V.C., ALMEIDA, L.B. Ocorrência de carotenóides em raízes de cinco cultivares de mandioca (Manihot esculenta Crantz) do Estado de São Paulo. Rev. Farm. Bioquím. Univ. São Paulo, São Paulo, v. 24, n. 1, p. 39-49, 1988.

[19] PROSKY,L Determination of insoluble, soluble and total dietary fiber in foods and products. Interlaboratory study. J. Assoc. Off. Anal. Chem., Washington, v. 71, p. 1017-1023,1988.
[20] REEVES, P. G., NIELSEN, F.H., FAHEY, G.C. AIN-93 Purified diets for laboratory rodents: final reprt of the American Institute of Nutrition ad hoc writing committe on the reformulation of the AIN-76A rodent diet. J. Nutr., Philadelphia, v. 123, p. 1939-1951, 1993.

[21] RETTENMAIER, R., SHÜEP, W. Determination of vitamins $\mathrm{A}$ and $\mathrm{E}$ in liver tissue. Int. J. Vitam. Nutr. Res., Bern, v. 62, p. 312-317, 1992.

[22] ROCK, C.L., SWENDSEID, M.E. Plasma $\beta$-carotene response in humans after meals supplemented with dietary pectin. Am. J. Clin. Nutr., Bethesda, v. 55, p. 96-99, 1992.

[23] RODRIgueZ, D.B., RAYMUndo, L.C., LEE, T.C., SIMPSON, K.L., CHICHESTER, C.O. Carotenoids pigments changes in ripening Momordica charantia fruits. Ann. Bot., London, v. 40, p. 615-624, 1976.

[24] SCHMITZ, H.H., POOR, C.L., WELMAN, R.B., ERDMAN Jr., J.W. Concentration of selected carotenoids and vitamin a in human liver, kidney, and lung tissue. J. Nutr., Philadelphia, v. 121, p 1613-1621, 1991.

[25] SWEENWY, J.P. , MARSH, A.C. Liver storage of vitamin A in rat fed carotene stereoisomers. J. Nutr., Philadelphia, v. 103, p. 20-25, 1973.

[26] TANUMIHARDJO, S.A. Facrors influencing the conversion of carotenoids to retinol: bioavailability to bioconversion to bioefficacy. Int. J. Vitam. Nutr. Res., Bern, v. 72, n. 1, 2002.

[27] THURNHAM, D.I., SMITH, E., FLORA, P. S. Concurrent liquid-chromatographic assay of retinol, $\alpha$-tocopherol, $\beta$-carotene, a-carotene, lycopene, and $\beta$-cryptoxanthin in plasma, with tocopherol acetate as internal standard. Clin. Chem., Winston Salem, v. 34, n. 2, p. 377-81, 1988.

[28] TEE, E.S., LIM, C.L., CHONG, Y.H, KHOR, S.C. A study of the biological utilization of carotenoids of carrots and swamp cabbage in rats. Food Chem., Barking, v. 56, n. 1 p. 21-32, 1996.

[29] WANG, X-D. Review: Absorption and metabolism of $\beta$ carotene. J. Am. Coll. Nutr., New York, v. 13, n. 4, p. 314-325, 1994. 